\title{
A supplement to
}

\section{Chemical composition and oxidative potential of atmospheric $\mathrm{PM}_{10}$ over the Arabian Sea}

$$
\text { Anil Patel and Neeraj Rastogi* }
$$

Geosciences Division, Physical Research Laboratory, Ahmedabad, India

*Corresponding Author

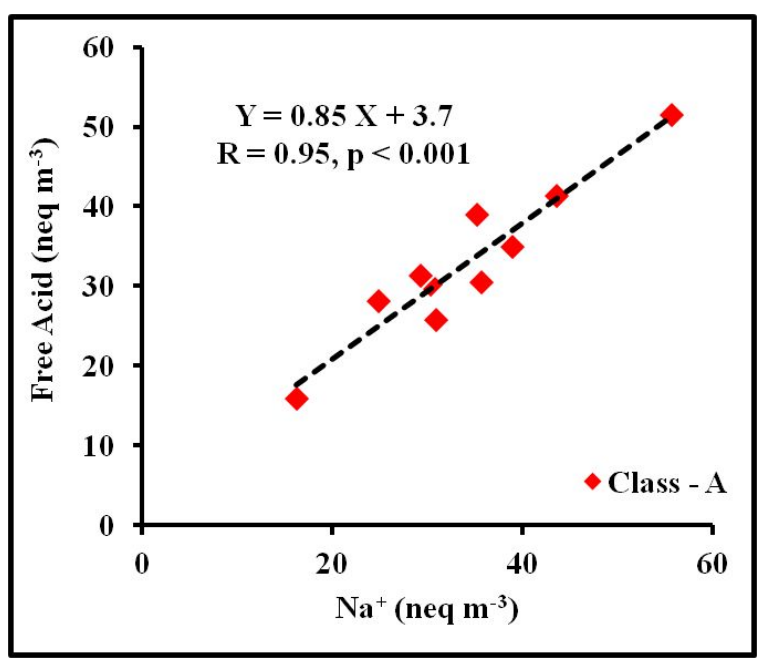

Figure S1. Scatter plot between free acid and $\mathbf{N a}^{+}$for Class-A samples, indicating chemical interaction between sea-salts and acidic species. 


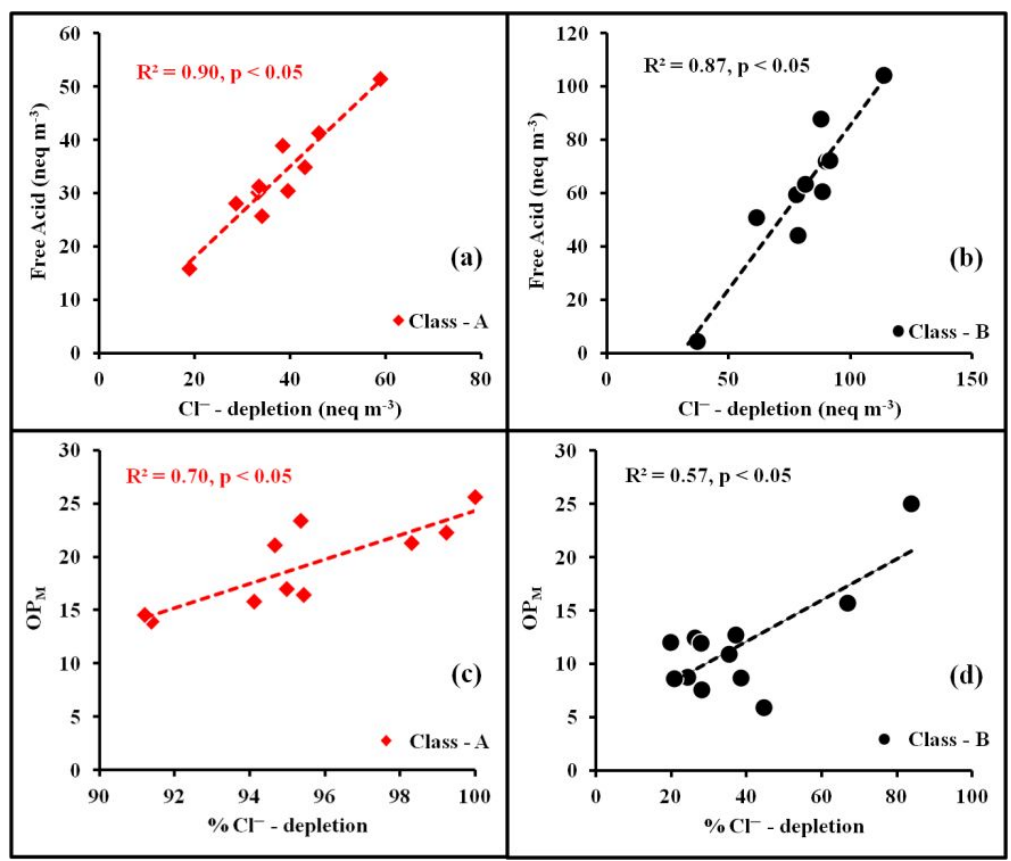

Figure S2. Scatter plots showing linear regression between free acid (equivalent units) and $\mathbf{C l}^{-}$depletion for (a) Class-A and (b) Class-B; and plots between $\mathrm{OP}_{\mathrm{M}}$ and $\% \mathbf{C l}^{-}$-depletion for (c) Class-A and (d) Class-B samples. This suggests the role of free acidity on $\mathrm{OP}_{\mathrm{M}}$. 


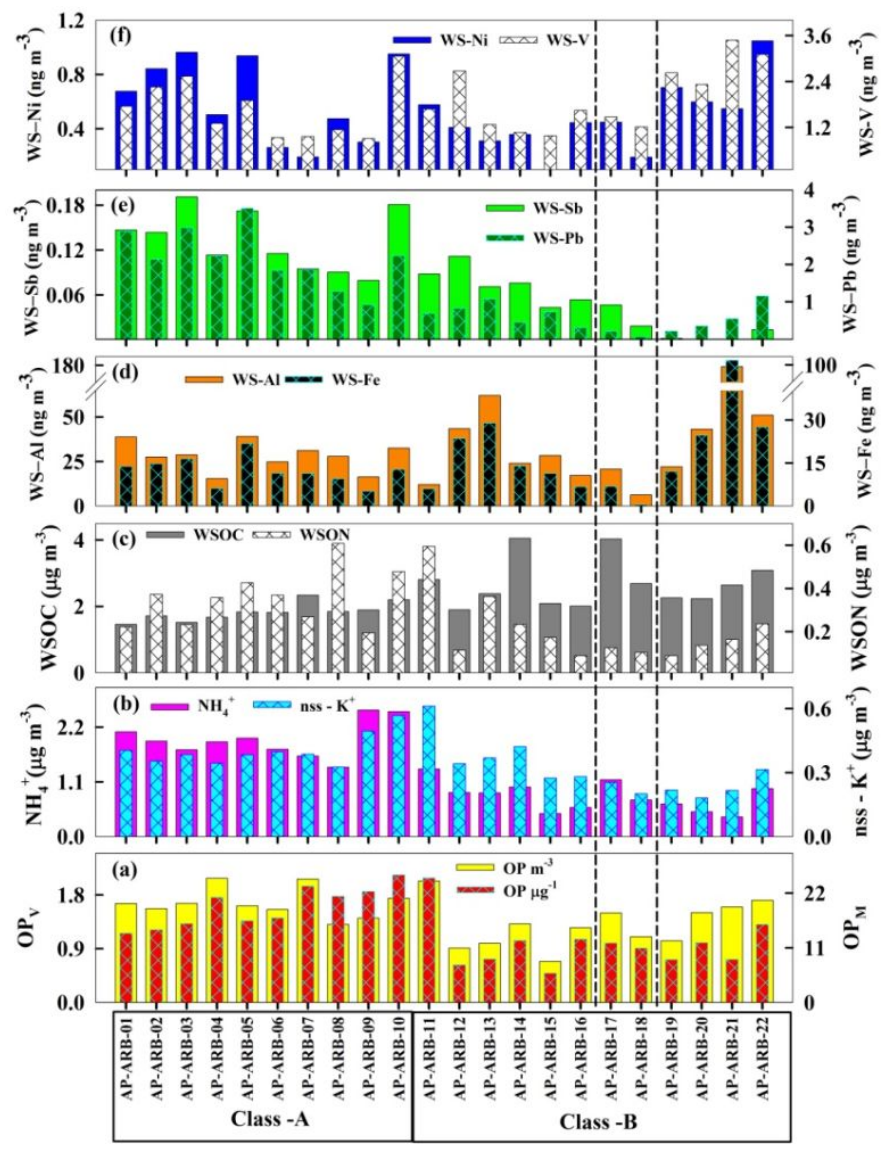

Figure S3. Temporal variability of (a) $\mathrm{OP}_{\mathrm{V}}$ and $\mathrm{OP}_{\mathrm{M}}$, (b) $\mathbf{N H}_{\mathbf{4}}^{+}$and nss-K $\mathbf{K}^{+}$, (c) WSOC and WSON, (d) water soluble (WS)-Al and WS-Fe, (e) WS-Sb and WS-Pb, and (f) WS-Ni and WS-V. Two samples appeared to be affected by chimney emissions based on OC/EC and nss$\mathbf{K}^{+} / \mathrm{EC}$ ratios (see Fig. S4). They are highlighted between dotted lines. 


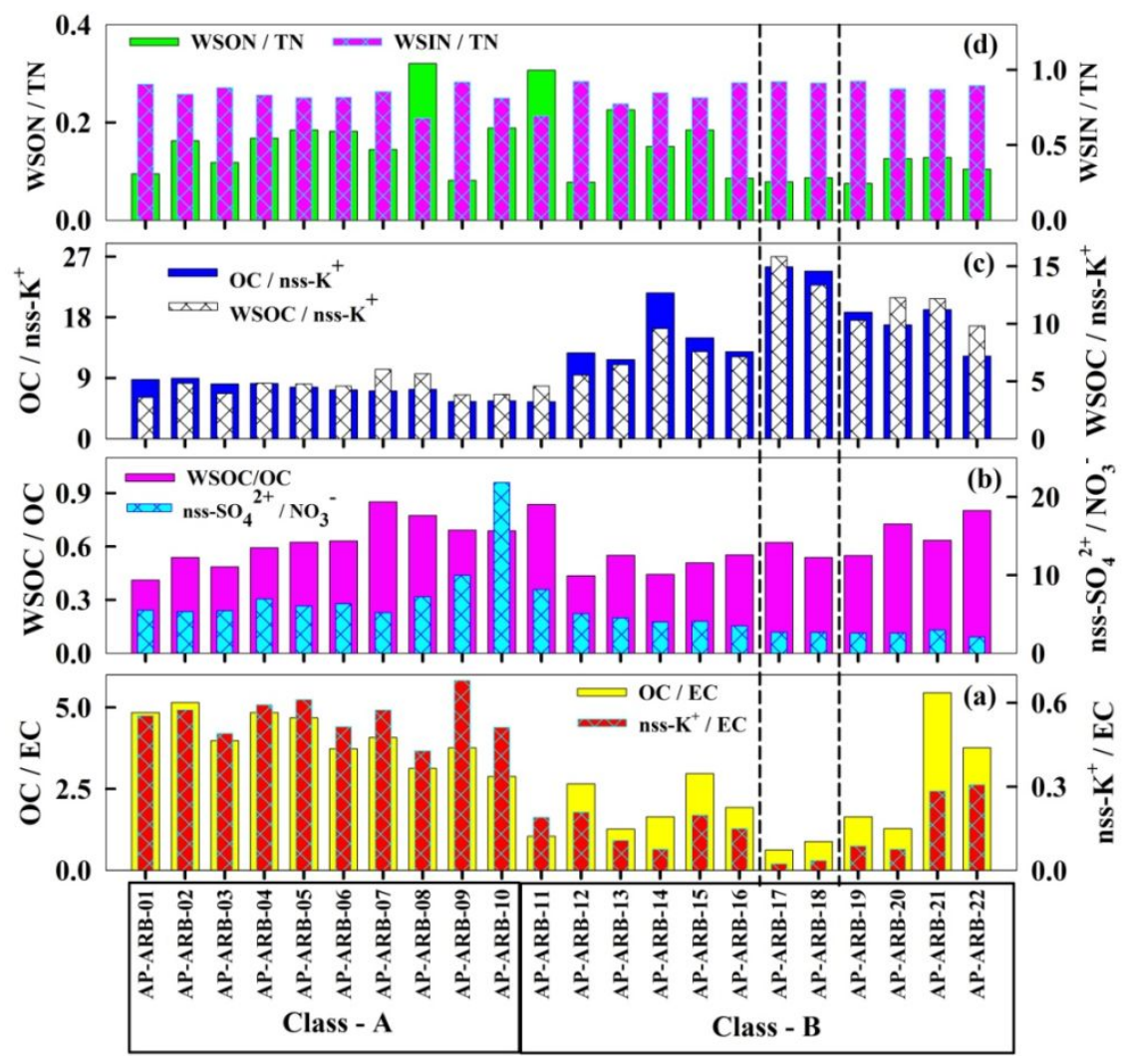

Figure S4. Temporal variability of different characteristic ratios such as (a) $\mathrm{OC} / \mathrm{EC}$ and nss- $\mathbf{K}^{+}$ /EC (b) $\mathrm{WSOC} / \mathrm{OC}$ and $\mathrm{nss}-\mathbf{S O}_{4}^{2-} / \mathbf{N O}_{3}^{-}$(c) $\mathrm{OC} / \mathrm{nss}^{-} \mathrm{K}^{+}$and $\mathrm{WSOC} / \mathrm{nss}^{-} \mathrm{K}^{+}$and (d) $\mathrm{WSON} / \mathrm{TN}$ and WSIN/TN. 